\title{
Lack of association between $A C E$ I/D, NOS3 VNTR polymorphisms and drug toxicity of tacrolimus treated post-renal transplantation patients
}

\author{
Kathulapali Krishna $^{1^{\circledR}}$, Sanjana Satheesh ${ }^{2}{ }^{\circledR}$, Gnanasambandan Ramanathan $^{2}{ }^{\circledR}$, Solomon F. D. Paul ${ }^{3}$, \\ Jayakumar Matcha $^{1}{ }^{\mathbb{D}}$, Ramprasad Elumalai $^{1 * \mathbb{D}}$ \\ ${ }^{1}$ Department of Nephrology, Sri Ramachandra Institute of Higher Education and Research, Chennai, India \\ ${ }^{2}$ Department of Biomedical Sciences, Sri Ramachandra Institute of Higher Education and Research, Chennai, India \\ ${ }^{3}$ Department of Human Genetics, Sri Ramachandra Institute of Higher Education and Research, Chennai, India
}

\section{A R T I C LE IN F O}

Article Type:

Original

\section{Article History:}

Received: 30 August 2019

Accepted: 30 October 2019

Published online: 5 December 2019

\section{Keywords:}

Tacrolimus

ACE I/D

NOS3 VNTR

Transplantation

Polymorphisms

End-stage renal disease

Calcineurin inhibitors

\begin{abstract}
A B S T RA C T
Introduction: Tacrolimus is the most commonly used calcineurin inhibitor for renal transplant individuals. Genetic factors play a major role in allografts by affecting blood pressure regulation, vascular proliferation and inflammatory responses.

Objectives: The aim of this study was to evaluate a possible role of the ACE I/D and NOS3 VNTR polymorphisms in kidney transplantation patients treated with tacrolimus in the south Indian population.

Patients and Methods: This study included 50 kidney transplant individuals and 100 unrelated healthy individuals from the general population as control. The genotyping was performed by polymerase chain reaction and electrophoresis. Genotypes were compared among cases and controls applying $\chi 2$ test. The difference in C/D ratios was compared using Mann-Whitney $\mathrm{U}$ test or Kruskal-Wallis test.

Results: The ACE ID polymorphisms in different models [genetic $(P=0.723)$, dominant $(P=0.148)$ and recessive $(P=0.652)]$ or allele model $(P=0.455)$ did not differ significantly between the groups. Similarly, there was no significant difference for the NOS3 VNTR genotypes in genetic model ( $\mathrm{bb} v s$ ba $P=0.118$; bb $v s$ aa $P=0.446$ ), dominant model ( $\mathrm{bb} v s$ ba $+\mathrm{aa}$ $P=0.099$ ) and allelic model (b vs a $P=0.103$ ). No significant difference was observed for $A C E$ $I D$ and NOS3 VNTR genotypes between the toxicity and non-toxicity groups. Furthermore, no significant association was observed for daily dose and concentration dose ratio for the studied polymorphisms.

Conclusion: The present study revealed no significant association between cases and controls as well as toxicity and non-toxicity groups. Furthermore, there was no association between genotypes and daily dose and dose concentration.
\end{abstract}

Implication for health policy/practice/research/medical education:

To evaluate a possible role of the ACE I/D and NOS3 VNTR polymorphisms in the kidney transplantation patients treated with tacrolimus in south Indian population, we conducted a study on 50 kidney transplant individuals. Our study revealed the absence of a significant association between cases and controls as well as toxicity and non-toxicity groups. Furthermore, the association between genotypes and daily dose and dose concentration was also not observed.

Please cite this paper as: AS. Lack of association between ACE I/D, NOS3 VNTR polymorphisms and drug toxicity of tacrolimus treated post-renal transplantation patients. J Nephropharmacol. 2020;9(2):e19. DOI: 10.34172/npj.2020.19.

\section{Introduction}

End-stage renal disease (ESRD) is a major health problem, associated with morbidity and mortality. The renal transplantation option is the best therapy, far superior to dialysis in patients with ESRD (1). Tacrolimus is the most commonly used calcineurin inhibitor for renal transplant individuals. However, the graft function is multifactorial which includes, primary disease, immunosuppressive regimen, metabolic and cardiovascular conditions, episodes of acute rejection and donor and recipient ages (2). Furthermore, the genetic factors also play a major role in the allografts by affecting blood pressure regulation, vascular proliferation and inflammatory responses (3). Further studies have also confirmed the 
associations of genetic variation with immunosuppressant pharmacokinetics, toxicity, and outcomes after transplantation (4-6).

Among the different pathways which regulate the allografts, the renin angiotensin aldosterone system (RAAS) is an independent factor for progression of renal attrition and ESRD (7). Therefore, genetic polymorphism of RAAS might be the most important mediator of renal allograft among transplanted individuals. Further, the RAAS activity is regulated by an angiotensin-converting enzyme (ACE) gene by converting angiotensin I into vasoactive and aldosterone stimulating peptide angiotensin II (8). Among the several polymorphisms of ACE gene, the $A C E$ insertion/deletion (I/D) gene polymorphism is found to be more frequently associated with renal allograft survival after renal transplantation. In past years, several studies have investigated the association between $A C E$ I/D polymorphism and renal transplantation yielding inconsistent results (9-11). Similarly, the endothelial nitric oxide synthase gene polymorphisms affect the renal rejection through the endothelial nitric oxide synthase activity and endothelial dysfunction. Among the several functional polymorphisms of NOS3 gene, the VNTR polymorphisms can alter renal function (12). Recent studies conducted in Iranian kidney transplant recipients and chronic allograft nephropathy in Turkey population have found, no significant association between the allele/ genotype and acute rejection $(13,14)$. So far, no studies have shown the association of ACE I/D and NOS3 VNTR polymorphisms with renal rejection in our population. Therefore, the present study aimed to investigate the possible correlation between ACE I/D and NOS3 VNTR polymorphisms with renal transplantation individuals treated with tacrolimus.

\section{Objectives}

The aim of this study was to evaluate a possible role of the ACE I/D and NOS3 VNTR polymorphisms in kidney transplantation patients treated with tacrolimus in the south Indian population.

\section{Patients and Methods \\ Study patients}

The present study investigated fifty individuals of postrenal transplantation patients (male $76 \%$; female $34 \%$ and age was $35.0 \pm 13.23$ ) treated with tacrolimus based immunosuppressive as the outpatient and inpatient wings of the Nephrology Department of Sri Ramachandra Institute of Higher Education and Research, and hundred unrelated healthy individuals from general population as the control subjects (male 64\%; female 36\% and age was $53.9 \pm 12.9$ years). For all transplant individuals, the tacrolimus levels in blood were measured using the chemiluminescent microparticle immunoassay (CMIA) method. The trough $\mathrm{C}_{0}(\mathrm{ng} / \mathrm{mL})$ level, was revised by dose and patient's body weight. Moreover, based on the tacrolimus toxicity the subjects were divided into two groups such as toxicity (18\%) and non-toxicity groups $(82 \%)$.

\section{Genotyping}

Human genomic DNA was extracted from peripheral blood specimens by phenol chloroform extraction and ethanol precipitation method(15). The polymerase chain reaction (PCR) and electrophoresis were used to detect the ACE gene insertion deletion (16) and NOS3 VNTR polymorphism (12). All homozygous deletion of $A C E$ gene were further subjected to a second PCR amplification with insertion-specific primers to prevent mistyping of heterozygous genotypes (17).

\section{Ethical issues}

Human rights were respected under the Helsinki Declaration 1975, as revised in 1983. The study protocol was approved by the Institutional Ethics Committee of Sri Ramachandra Institute of Higher Education and Research, Chennai, India. Informed consent was obtained from all the study participants before collecting the blood samples.

\section{Statistical analysis}

The direct gene-counting method was adapted to calculate allele frequencies. The distribution of genotypes was tested for Hardy-Weinberg equilibrium using the $\chi 2$ goodnessof-fit test. A $\chi 2$ test was carried out to check the association between cases $v s$ controls. Odds ratios (ORs) and 95\% CIs were calculated. The SPSS (version 16.0; SPSS, Chicago, IL) was applied to evaluate the association amongst the genetic variants and $P$ values $<0.05$ were considered to be statistically significant. The tacrolimus $\mathrm{C} / \mathrm{D}$ ratios are expressed as median $\pm \mathrm{SD}$ range. The difference in $\mathrm{C} / \mathrm{D}$ ratios was compared using Mann-Whitney $U$ test or Kruskal-Wallis test among groups.

\section{Results}

Association analysis between the ACE ID, NOS3 VNTR polymorphism and subjects

For this study were genotyped 50 kidney transplanted individuals treated with tacrolimus and 100 unrelated healthy individuals were genotyped. Of the studied 100 control subjects the II, ID and DD were 40 (40\%), 41 (41\%) and 19 (19.0\%), respectively, and of the studied 50 renal post-transplantation patients treated with tacrolimus were II 14 (28\%), ID 28 (56\%) and DD 8 (16\%). For NOS3 VNTR the observed genotyped frequencies of controls were bb 75 (75.0\%), bb $21(21 \%)$ and aa $3(3 \%)$. For the renal transplantation cases bb were $31(62.0 \%)$, ba were $16(32.0 \%)$ and aa were $4(4.0 \%)$ (Table 1$)$. The genotype frequencies of kidney transplanted individuals treated with tacrolimus and control group were in accordance with the HWE for both polymorphisms. The ACE ID polymorphisms in different models (genetic $(P=0.723)$, dominant $(P=0.148)$ and recessive $(P=0.652))$ or allele 
Table 1. Association between the studied subjects and ACE ID, NOS3 VNTR polymorphism

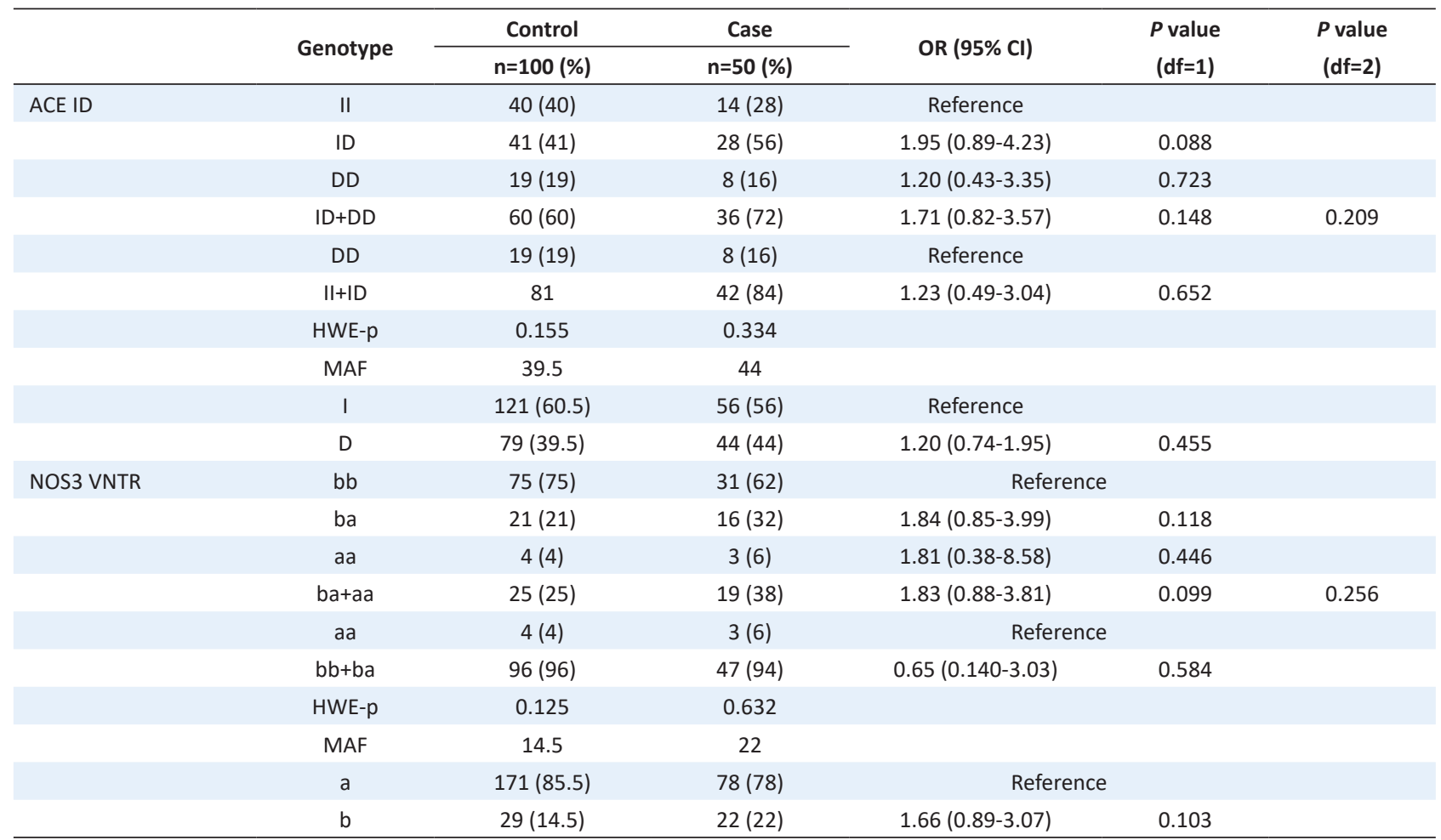

${ }^{*} \chi^{2} \mathrm{p}$ value. OR: odds ratio; $\mathrm{Cl}$ : confidence interval.

model $(P=0.455)$ did not differ significantly between the groups. Similarly, there was no significant difference for the NOS3 VNTR genotypes between the control and case in genetic model (bb $v s$ ba $P=0.118$; bb $v s$ aa $P=0.446$ ), dominant model (bb vs ba+aa $P=0.099$ ) and allelic model (b vs a $P=0.103$ ).

Drug toxicity among kidney transplanted individuals and genotypes

The genotype distribution of ACE ID and NOS3 VNTR polymorphisms between the non-toxicity and toxicity groups are presented in Table 2. There was no significant difference for ACE ID genotypes between the toxicity and non-toxicity groups in genetic (II $v s$ ID OR $=0.80,95 \% \mathrm{CI}$ $=(0.16-3.95)$; (II vs DD OR=0.52,95\% CI = (0.04-6.09)), dominant (II $v s$ ID $+\mathrm{DD} \mathrm{OR}=0.73,95 \% \mathrm{CI}=(0.15-3.45)$ and allelic models (I vs D OR $=0.77,95 \% \mathrm{CI}=(0.27-2.19)$ (Table 2). Furthermore, the other studied NOS3 VNTR polymorphisms also revealed the absence of significant association between the non-toxicity and toxicity groups in genetic $(P=0.703)$, dominant $(P=0.75)$ and allelic models $(P=0.546)$ (Table 2$)$. These results suggest that

Table 2. Association between toxicity and non-toxicity among the kidney transplantation patients

\begin{tabular}{|c|c|c|c|c|c|c|}
\hline \multirow{2}{*}{ Gene } & \multirow{2}{*}{ Genotypes } & No Toxicity & Toxicity & \multirow{2}{*}{ OR $(95 \% \mathrm{Cl})$} & \multirow{2}{*}{$\begin{array}{c}P \text { value } \\
\mathrm{df}=1\end{array}$} & \multirow{2}{*}{$\begin{array}{c}P \text { value } \\
\mathrm{df}=2\end{array}$} \\
\hline & & $n=41(\%)$ & $n=9(\%)$ & & & \\
\hline \multirow[t]{6}{*}{ ACE ID } & $\|$ & $11(26.8)$ & $3(33.3)$ & Reference & & \\
\hline & ID & $23(56.1)$ & $5(55.5)$ & $0.80(0.16-3.95)$ & 0.781 & \\
\hline & DD & $7(17.0)$ & 1 (11.1) & $0.52(0.04-6.09)$ & 0.601 & \\
\hline & $I D+D D$ & $30(73.1)$ & $6(66.6)$ & $0.73(0.15-3.45)$ & 0.693 & 0.871 \\
\hline & 1 & 45 (54.9) & $11(61.1)$ & Reference & & \\
\hline & $\mathrm{D}$ & $37(45.1)$ & 7 (38.9) & $0.77(0.27-2.19)$ & 0.629 & \\
\hline \multirow[t]{6}{*}{ NOS3 VNTR } & $\mathrm{bb}$ & $25(60.9)$ & $6(66.6)$ & Reference & & \\
\hline & ba & $13(31.7)$ & $3(33.3)$ & $0.96(0.20-4.48)$ & 0.96 & \\
\hline & aa & $3(7.3)$ & $0(0)$ & & & 0.703 \\
\hline & ba+aa & $16(39.0)$ & $3(33.3)$ & $0.78(0.17-3.57)$ & 0.75 & \\
\hline & $\mathrm{b}$ & $63(76.8)$ & $15(83.3)$ & Reference & & \\
\hline & $\mathrm{a}$ & $19(23.2)$ & $3(16.7)$ & $0.66(0.17-2.53)$ & 0.546 & \\
\hline
\end{tabular}


both ACE ID and NOS3 VNTR polymorphisms were are not susceptible genes for drug toxicity among the kidney transplanted patients treated with tacrolimus.

\section{Effect of ACE ID and NOS3 VNTR genetic polymorphisms} on tacrolimus daily requirements and concentration/ dose ratio

The distribution of ACE ID and NOS3 VNTR polymorphisms between the tacrolimus daily dose and concentration dose ratio of renal transplant patients is documented in Table 3 . The daily dose required for II genotype was more than the other ID and DD genotype. Contradictory to this, the concentration dose ratio was more for DD genotype compared to other II and ID genotypes. However, there was no significant association between daily dose $(P=0.910)$ and concentration dose ratio $(P=0.461)$. For NOS 3 VNTR polymorphisms, a high dose is required for aa genotype when compared to $\mathrm{bb}$ and ba. However, the concentration dose ratio for bb is very high when compared to the ba and aa. However, no significant difference was observed for daily dose $(P=0.515)$ and concentration dose ratio $(P=0.884$; Table 3).

\section{Discussion}

Genetic polymorphisms regulating RAAS, in organ transplant recipients might affect kidney function as independent factor (18). In the present study, the association between ACE I/D, NOS3 VNTR gene polymorphisms and kidney transplant patients treated with tacrolimus was analyzed. There was no significant association between the cases and the controls as well as toxicity and non-toxicity groups.

Several studies have investigated the relationship between ACE I/D gene polymorphism and patient survival after kidney transplantation. However, these studies have yielded inconclusive results. In a genome-wide association study, O'Brien et al recognized two variants which had genome-wide significance for long-term graft survival and allograft function in kidney transplant recipients (19). Another study by Akcay et al suggested the DD variant of the ACE gene polymorphism might be associated with increased risk of developing chronic allograft dysfunction (20). A very recent meta-analysis study also observed the significant association between allograft rejections, allograft function and ACEI/D polymorphism. Furthermore, they suggested that the early identification of ACE I/D genotype can significantly improve the outcome of patients(3). Similarly, the other meta-analysis also revealed that the ACE D allele and DD genotype to be associated with renal allograft survival after renal transplantation (21). In contradictory to this study, Azmandian et al in 2015 found that donor and recipient ACE-DD genotype might not be a risk factor for acute renal allograft rejection. Similarly, the present study also revealed the absence of significant association between cases and controls.

Several studies have discussed the role of nitric oxide and allograft rejection in liver, heart, kidney, and pancreatic islet cell transplant (22-25). Further studies have also proved a significant increase in serum NO levels during episodes of rejection in renal transplant recipients $(24,26)$. Furthermore, in the past decades, several association studies were conducted between the NOS3 gene polymorphisms and chronic allograft nephropathy. Yilmaz et al in 2009 (14) and Viklicky et al in 2002 (27) studied G894T polymorphisms of NOS3 gene and revealed its influence is long-term renal allograft outcome and did not consider it as a risk factor for chronic allograft failure. In 2005 Sezer et al found that bb allele of the NOS3 gene was associated with an anti-inflammatory state and may predict renal outcome in transplant patients(28). Variant eNOS gene polymorphism, which produced decreased eNOS activity, was linked to worse remote graft function (29). Azarpira et al in 2013 revealed that the NOS 3 gene polymorphisms did not alter the risk of acute rejection after a renal transplant (13). Similarly, another study also found the absence of association between NOS3 gene and chronic renal transplant dysfunction (20). Even the current study results were also being in accordance with previous reports.

ACE, which is a key enzyme in the RAS system, catalyzes the conversion of angiotensin I to II in the liver and kidney. Evidence suggests that polymorphisms of the ACE gene may play an important role in pharmacokinetics and pharmacodynamics of tacrolimus (30). However, studies conducted on the association between ACE gene polymorphisms and renal dysfunction in adult recipients

Table 3. The effect of ACE ID and NOS3 VNTR genetic polymorphisms on tacrolimus daily requirements and concentration/ dose ratio at 3 month posttransplantation

\begin{tabular}{|c|c|c|c|c|}
\hline Genotype & $\begin{array}{l}\text { Daily Dose }(\mathrm{mg} / \mathrm{kg} / \mathrm{d}) \\
\text { Mean } \pm \text { SD }\end{array}$ & $P$ value & $\begin{array}{c}\text { Concentration dose ratio }(\mathrm{ng} / \mathrm{mL}) /(\mathrm{mg} / \mathrm{kg} / \mathrm{d}) \\
\text { Mean } \pm \mathrm{SD}\end{array}$ & $P$ value \\
\hline ACE II & $2.71 \pm 8.3$ & & $3.20 \pm 1.62$ & \\
\hline ID & $2.75 \pm 1.04$ & & $3.27 \pm 1.87$ & \\
\hline DD & $2.57 \pm 0.98$ & 0.910 & $4.27 \pm 3.0$ & 0.461 \\
\hline NOS3 bb & $2.74 \pm 0.96$ & & $3.38 \pm 2.36$ & \\
\hline ba & $2.63 \pm 1.02$ & & $3.40 \pm 1.32$ & \\
\hline aa & $3.33 \pm 0.58$ & 0.515 & $2.78 \pm 0.76$ & 0.884 \\
\hline
\end{tabular}


who received tacrolimus yielded inconsistent results. Chen et al study in the Chinese population where 90 consecutive de novo liver graft recipients who underwent livingdonor liver transplantation were studied revealed the absence of significant association between its genotypes and the disposition of tacrolimus (31). Another study on post-transplantation diabetes mellitus in Korean kidney transplanted individuals also showed the absence of significant association between ACE polymorphisms and tacrolimus, however, the effect of AGT polymorphisms on post-transplantation diabetes mellitus remained significant (32). However, a study from cosmopolitan city in south India revealed the DD genotype and D allele of ACE gene polymorphism to be associated with post-transplantation diabetes mellitus (33). The present study, though from the south Indian population, failed to observe such association between tacrolimus dose or concentration and post-renal transplantation patients.

\section{Conclusion}

In conclusion, the present study revealed the absence of a significant association between cases and controls as well as toxicity and non-toxicity groups. Furthermore, the association between genotypes and daily dose and dose concentration was also not observed. However, further studies are warranted with large number of patients to find the proper impact of genetic polymorphisms on tacrolimus.

\section{Limitations of the study}

The main limitations of this study were the retrospective design from a single center and a limited number of patients. Further, the confounding effect of that which may have affected tacrolimus pharmacokinetics was not examined. Finally, the data of the donor individuals were not collected for comparisons.

\section{Acknowledgments}

The authors would like to thank Sri Ramachandra Institute of Higher Education and Research for providing necessary facilities and the subjects.

\section{Authors' contribution}

$\mathrm{RE}$; the concept, design, manuscript preparation and final revision. KK \& SS; performing experiments and data collection and writing proposal. GR; statistical analysis, manuscript editing, and manuscript review. SFDP; genetic data analysis, experiment design. JM; data collection and manuscript editing.

\section{Conflicts of interest}

The authors declare that they have no conflicts of interest.

Ethical considerations

Ethical issues (including plagiarism, data fabrication, double publication) have been completely observed by the authors.

\section{Funding/Support}

None.

\section{References}

1. Hod T, Goldfarb-Rumyantzev AS. Clinical issues in renal transplantation in the elderly. Clin transpl. 2015;29:167-75. doi: $10.1111 /$ ctr.12481.

2. Siekierka-Harreis M, Kuhr N, Willers R, Ivens K, Grabensee $\mathrm{B}$, Mondry A, et al. Impact of genetic polymorphisms of the renin-angiotensin system and of non-genetic factors on kidney transplant function--a single-center experience. Clin Transpl. 2009;23:606-15. doi: 10.1111/j.13990012.2009.01033.x.

3. Huang Z, Wu B, Tao J, Han Z, Yang X, Zhang L, et al. Association between Angiotensin I-Converting Enzyme Insertion/Deletion Polymorphism and Prognosis of Kidney Transplantation: A Meta-Analysis. PloS One. 2015;10:e0127320. doi: 10.1371/journal.pone.0127320.

4. Anglicheau D, Legendre C, Beaune P, Thervet E. Cytochrome P450 3A polymorphisms and immunosuppressive drugs: an update. Pharmacogenomics. 2007;8:835-49. doi: 10.2217/14622416.8.7.835.

5. Coto E, Tavira B. Pharmacogenetics of calcineurin inhibitors in renal transplantation. Transplantation. 2009;88:S62-7. doi: 10.1097/TP.0b013e3181afe9e7.

6. Ramanathan G, Sethumadavan P, Elumalai R, Durairaj Paul SF. Role of CYP2E1 (PstI/RsaI) gene polymorphisms on the tacrolimus drug toxicity of kidney transplantations among South Indians. Immunopathol Persa. 2016;2(2):e20.

7. Hunley TE, Julian BA, Phillips JA, 3rd, Summar ML, Yoshida H, Horn RG, et al. Angiotensin converting enzyme gene polymorphism: potential silencer motif and impact on progression in IgA nephropathy. Kidney Int. 1996;49:571-7.

8. Rigat B, Hubert C, Alhenc-Gelas F, Cambien F, Corvol P, Soubrier F. An insertion/deletion polymorphism in the angiotensin I-converting enzyme gene accounting for half the variance of serum enzyme levels. J Clin Invest. 1990;86:1343-6. doi: 10.1172/JCI114844.

9. Viklicky O, Hubacek JA, Pitha J, Teplan V, Heemann UW, Lacha J, et al. ACE gene polymorphism and long-term renal graft function. Clin Biochem. 2001;34(1):87-90.

10. Ayed K, Ayed-Jendoubi S, Ben Abdallah T, Bardi R, Gorgi Y, Sfar I, et al. Polymorphism of the renin-angiotensinaldosterone system in patients with chronic allograft dysfunction. Transpl Immunol. 2006;15:303-9. doi: 10.1016/j.trim.2005.09.011.

11. Zhang G, Wang $\mathrm{H}$, Wang $\mathrm{F}$, Yu L, Yang X, Meng J, et al. Gene polymorphisms of the renin-angiotensinaldosterone system and angiotensin II type 1-receptor activating antibodies in renal rejection. Tohoku J Exp Med. 2007;213:203-14.

12. Nath SD, He X, Voruganti VS, Blangero J, MacCluer JW, Comuzzie AG, et al. The 27-bp repeat polymorphism in intron 4 (27 bp-VNTR) of endothelial nitric oxide synthase (eNOS) gene is associated with albumin to creatinine ratio in Mexican Americans. Mol Cell Biochem. 2009;331:201-5. 
doi: 10.1007/s11010-009-0159-5.

13. Azarpira N, Aghdai MH, Geramizadeh B, Bahador A, Ayatolahi M, Darai M. Influence of endothelial nitric oxide synthase gene polymorphisms (-786T/C, 4a4b, 894G/T) on Iranian kidney transplant recipients. Exp Clin Transplant. 2013;11:21-6.

14. Yilmaz E, Mir S, Berdeli A. Endothelial nitric oxide synthase (eNOS) gene polymorphism in early term chronic allograft nephropathy. Transplant Proc. 2009;41:4361-5. doi: $\quad 10.1016 /$ j.transproceed.2009.09.080.

15. Sambrook J. Molecular Cloning: A Laboratory Manual 3rd ed. Cold Spring Harbor, NY: Cold Spring Harbor Laboratory Press; 2001.

16. Rigat B, Hubert C, Corvol P, Soubrier F. PCR detection of the insertion/deletion polymorphism of the human angiotensin converting enzyme gene (DCP1) (dipeptidyl carboxypeptidase 1). Nucleic Acids Res. 1992;25:1433.

17. Shanmugam V, Sell KW, Saha BK. Mistyping ACE heterozygotes. PCR Methods Appl. 1993;3:120-1.

18. Slowinski T, Diehr P, Kleemann P, Fritsche L, Renders L, Budde K, et al. No association between renin-angiotensin system gene polymorphisms and early and long-term allograft dysfunction in kidney transplant recipients. Nephrol Dial Transplant. 2004;19:2846-51. doi: 10.1093/ ndt/gfh483.

19. O’Brien RP, Phelan PJ, Conroy J, O'Kelly P, Green A, Keogan $\mathrm{M}$, et al. A genome-wide association study of recipient genotype and medium-term kidney allograft function. Clin Transplant. 2013;27:379-87. doi: 10.1111/ctr.12093.

20. Akcay A, Sezer S, Ozdemir FN, Arat Z, Atac FB, Verdi H, et al. Association of the genetic polymorphisms of the reninangiotensin system and endothelial nitric oxide synthase with chronic renal transplant dysfunction. Transplantation. 2004;78:892-8.

21. Yang $\mathrm{CH}, \mathrm{Lu} \mathrm{Y}$, Chen XX, Xian WF, Tu WF, Li HY. Assessment of the relationship between ACE I/D gene polymorphism and renal allograft survival. J Renin Angiotensin Aldosterone Syst. 2015;16:813-9. doi: $10.1177 / 1470320315574402$.

22. Stoica SC, Satchithananda DK, Atkinson C, Charman S, Goddard M, Large SR. Heat shock protein, inducible nitric oxide synthase and apoptotic markers in the acute phase of human cardiac transplantation. Eur J Cardiothorac Surg. 2003;24:932-9.

23. Albrecht EW, van Goor $\mathrm{H}$, Tiebosch AT, Moshage $\mathrm{H}$, Tegzess AM, Stegeman CA. Nitric oxide production and nitric oxide synthase expression in acute human renal allograft rejection. Transplantation. 2000;70:1610-6.
24. Bellos JK, Perrea DN, Theodoropoulou E, Vlachos I, Papachristodoulou A, Kostakis AI. Clinical correlation of nitric oxide levels with acute rejection in renal transplantation. Int Urol Nephrol. 2011;43:883-90. doi: 10.1007/s11255-010-9858-9.

25. Khanafer A, Ilham MA, Namagondlu GS, Janzic A, Sikas $\mathrm{N}$, Smith $\mathrm{D}$, et al. Increased nitric oxide production during acute rejection in kidney transplantation: a useful marker to aid in the diagnosis of rejection. Transplantation. 2007;84:580-6. doi: 10.1097/01.tp.0000278120.55796.42.

26. Joles JA, Vos IH, Grone HJ, Rabelink TJ. Inducible nitric oxide synthase in renal transplantation. Kidney int. 2002;61:872-5. doi: 10.1046/j.1523-1755.2002.00235.x.

27. Viklicky O, Hubacek JA, Vitko S, Heemann UW, Vasarhelyi B, Kohnle M, et al. G-protein beta-3-subunit and eNOS gene polymorphism in transplant recipients with long-term renal graft function. Kidney Blood Press Res. 2002;25:2459. doi: 10.1159/000066346.

28. Sezer S, Uyar M, Akcay A, Arat Z, Kulah E, Ozdemir $\mathrm{FN}$, et al. Endothelial nitric oxide synthase and angiotensin II type 1 receptor gene polymorphisms can influence chronic inflammatory state in renal transplant patients. Transplant Proc. 2005;37:776-8. doi: 10.1016/j. transproceed.2004.12.187.

29. Krajewska M, Koscielska-Kasprzak K, Weyde W, DrulisFajdasz D, Madziarska K, Mazanowska O, et al. Impact of donor-dependent genetic factors on long-term renal graft function. Transplant Proc. 2009;41:2978-80. doi: 10.1016/j. transproceed.2009.08.027.

30. Gijsen VM, Madadi P, Dube MP, Hesselink DA, Koren G, de Wildt SN. Tacrolimus-induced nephrotoxicity and genetic variability: a review. Ann Transplant. 2012;17:111-21.

31. Chen YK, Han LZ, Xue F, Shen CH, Lu J, Yang TH, et al. Personalized tacrolimus dose requirement by CYP3A5 but not $\mathrm{ABCB} 1$ or $\mathrm{ACE}$ genotyping in both recipient and donor after pediatric liver transplantation. PloS One. 2014;9:e109464. doi: 10.1371/journal.pone.0109464.

32. Lee SR, Moon JY, Lee SH, Ihm CG, Lee TW, Kim SK, et al. Angiotensinogen polymorphisms and post-transplantation diabetes mellitus in Korean renal transplant subjects. Kidney Blood Press Res. 2013;37:95-102. doi: 10.1159/000343404.

33. Vattam KK, Khan IA, Poornima S, Mukkavali KK, Rao P, Hasan Q. Exploration of insertion/deletion polymorphism of angiotensin converting enzyme in posttransplant diabetes mellitus individuals from an Asian Indian population. J Diabetes Metab 2014;5:428. doi: 10.4172/2155-6156.1000428.

Copyright $\odot 2020$ The Author(s); Published by Published by Society of Diabetic Nephropathy Prevention. This is an open-access article distributed under the terms of the Creative Commons Attribution License (http://creativecommons.org/licenses/by/4.0), which permits unrestricted use, distribution, and reproduction in any medium, provided the original work is properly cited. 